
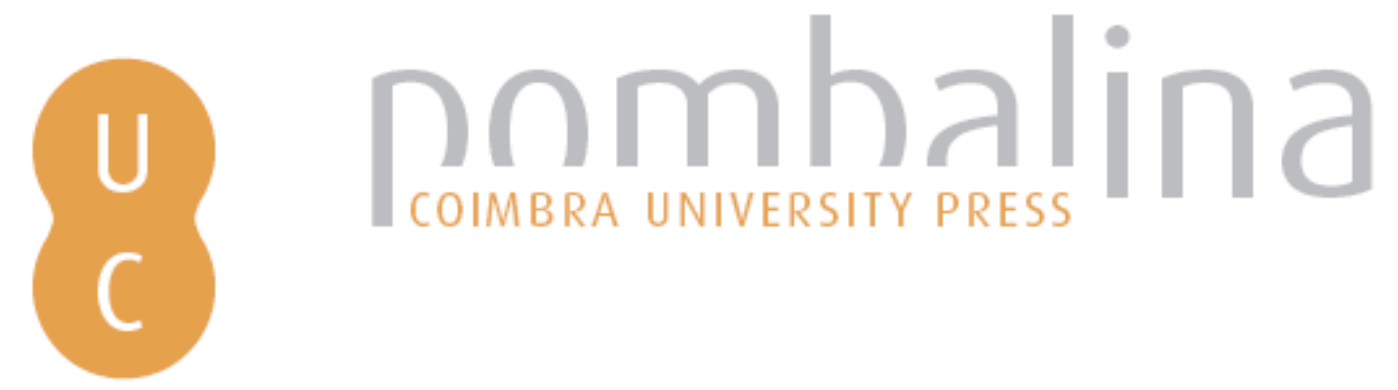

\title{
Configuração epistemológica da ciência da informação na literatura periódicabrasileira por meio de análise de citações (1972-2008)
}

\author{
Autor(es): $\quad$ Bufrem, Leilah Santiago; Arboit, Aline Elis; Freitas, Juliana Lazzaroto de \\ Publicado por: Imprensa da Universidade de Coimbra \\ URL \\ persistente: URI:http://hdl.handle.net/10316.2/31878 \\ DOI: $\quad$ DOI:http://dx.doi.org/10.14195/978-989-26-0319-3_15 \\ Accessed : $\quad$ 26-Apr-2023 05:55:39
}

A navegação consulta e descarregamento dos títulos inseridos nas Bibliotecas Digitais UC Digitalis, UC Pombalina e UC Impactum, pressupõem a aceitação plena e sem reservas dos Termos e Condições de Uso destas Bibliotecas Digitais, disponíveis em https://digitalis.uc.pt/pt-pt/termos.

Conforme exposto nos referidos Termos e Condições de Uso, o descarregamento de títulos de acesso restrito requer uma licença válida de autorização devendo o utilizador aceder ao(s) documento(s) a partir de um endereço de IP da instituição detentora da supramencionada licença.

Ao utilizador é apenas permitido o descarregamento para uso pessoal, pelo que o emprego do(s) título(s) descarregado(s) para outro fim, designadamente comercial, carece de autorização do respetivo autor ou editor da obra.

Na medida em que todas as obras da UC Digitalis se encontram protegidas pelo Código do Direito de Autor e Direitos Conexos e demais legislação aplicável, toda a cópia, parcial ou total, deste documento, nos casos em que é legalmente admitida, deverá conter ou fazer-se acompanhar por este aviso.

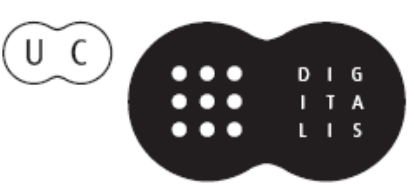


Maria Manuel Borges

Elias Sanz Casado

Coordenação

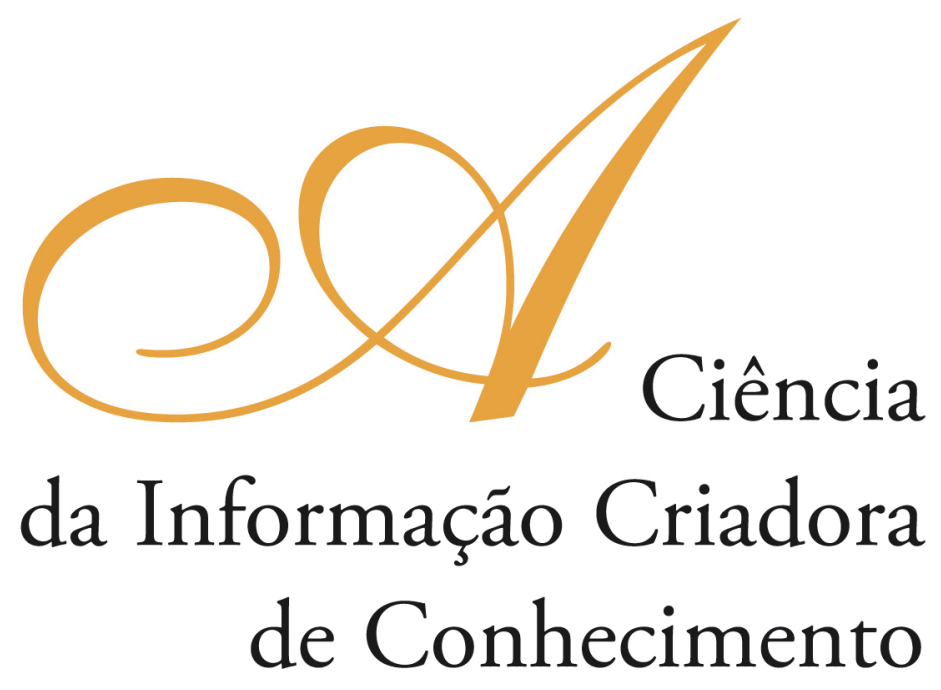

Vol. I

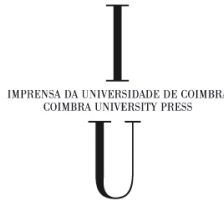

- COIMBRA 2009 


\title{
Configuração epistemológica da Cî̂ncia da Informação na literatura

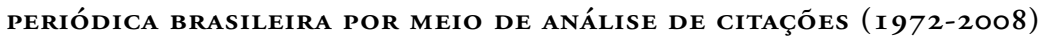

\section{Leilah Santiago Bufrem}

Universidade Federal do Paraná (Brasil)

\author{
Aline Elis Arboit \\ Universidade Federal do Paraná (Brasil) \\ Juliana Lazzaroto de Freitas \\ Universidade Federal do Paraná (Brasil)
}

\section{Resumo}

Descreve a configuração epistemológica da Ciência da Informação (CI) com base na análise de citações da produção periódica brasileira da área. Para tanto, busca aporte teórico nos conceito de epistemologia procurando estabelecer um diálogo com alguns autores da área que abordam o tema epistemologia da Ciência da Informação. Considerando o periódico como um dos principais veículos de comunicação científica, descreve o desenvolvimento e situação da produçáo periódica em CI no Brasil, apresentando a Base de Dados Referenciais de Artigos de Periódicos de Ciência da Informação (BRAPCI) como fonte representativa dos artigos sobre o tema, entre 1972 e 2008. Estes constituem o corpus da pesquisa, do qual foram selecionados 95 artigos registrados na base que versam sobre o tema Epistemologia da CI. Dentro deste recorte, foram levantados os dez autores mais representativos e realizada a análise de citaçóes dos trabalhos por eles produzidos por eles. Verifica e representa graficamente a incidência de citaçóes dos autores constituintes da base BRAPCI e também dos teóricos basilares da área de epistemologia mais citados. Identifica, deste modo, os autores nacionais basilares da epistemologia da CI no Brasil, bem com as influências dos autores provenientes do campo epistemológico na literatura periódica da área. Verifica que os autores da área foram influenciados e acompanharam as tendências do debate ocorrido no campo filosófico em torno da epistemologia.

\begin{abstract}
Study on theoretical setting related to the epistemological questions of Information Science (IS), based on the theoretical context analysis of Brazilian regular production in this area. It seeks theoretical input on epistemology concept, aiming to establish a dialogue with authors whose texts relate its concept to the IS. Examines how these producers of knowledge were affected and followed the trends of the debate in the philosophical field around epistemology. Considering this periodical as a major vehicle of science communication to analyze this production, bases itself on the Reference Database of Information Science periodical articles (BRAPCI), access source to records of articles published by Brazilian periodicals in the area since 1970, constituents of this research corpus. From BRAPCI were selected 95 articles on the topic IS Epistemology, to proceed to the citations analysis and author, identifying the ten most productive authors; graphically represents the incidence of citations of the constituent authors of the basis and also the fundamental epistemology theoreticians most cited in this corpus. Thus, it identifies the
\end{abstract}


national prominence authors in the theoretical context of IS in Brazil, as well as the influences of the authors from the epistemological field on this area's periodical literature.

\section{Introdução}

A epistemologia pode ser considerada o principal suporte de qualquer ciência, já que por meio dela se analisam seus fundamentos, seu vir a ser, suas relaçóes entre teoria e prática. Para a Ciência da Informação (CI), os estudos sobre questóes epistemológicas tornam-se fundamentais, pois diversamente das ciências convencionais como a Física ou a Química, ela é dotada de um alto grau de complexidade em função da sua recente consolidação e do seu multifacetado objeto de estudo: a informação.

Considerando-se que o desenvolvimento de uma ciência é refletido na produção científica, ou seja, que por meio das publicaçóes a comunidade científica tem acesso a um novo conhecimento e o torna legitimo, o estudo da comunicação científica possibilita o exame e a avaliação dos conteúdos produzidos pelos cientistas, bem como as tendências, métodos e influências teóricas. Neste contexto, desde o século XVII, o periódico científico figura como um dos mais importantes veículos de comunicação pois proporciona disseminação, formalização, atualização com rapidez, ampliação e precisão dos conhecimentos científicos.

A análise de citaçôes em artigos científicos tem sido uma metodologia largamente utilizada para investigar o comportamento das produçôes científicas, tendências e influências de pensamento, avaliação de conteúdos, categorias, linhas e enfoques. Assim, busca-se aqui descrever o estágio atual da configuração epistemológica da CI no Brasil via análise de citaçóes da produção periódica nacional. O objetivo do trabalho consiste em responder a seguinte questão: Como se configuram as questôes epistemológicas no campo da CI no Brasil, segundo a análise de citaçôes na literatura periódica da área?

$\mathrm{O}$ corpus da pesquisa é constituído pelos artigos registrados na base de dados referenciais de artigos de periódicos de Ciência da Informação (BRAPCI), do qual foram selecionados 95 trabalhos que versam sobre o tema epistemologia da CI, no período entre 1972 e 2008. Em seguida, foram levantados os teóricos constituintes da base BRAPCI e os teóricos fundamentais da área de epistemologia mais citados pelos dez autores mais produtivos da área. Deste modo, foi possível apontar os autores nacionais basilares da área da epistemologia da CI no Brasil, e os autores do pensamento epistemológico mais influentes na área. Concebe-se, para este estudo, a CI em seu sentido mais amplo, relacionada com um dominio que abrange a origem, coleta, organização, armazenamento, recuperação, interpretação, transmissão, transformação $e$ utilização da informação. Ao focar essa ciência, mais especificamente, as revistas que a representam no Brasil, amplia-se a investigação, para as representaçóes da informação, o uso de códigos para uma eficiente transmissão de mensagens e o estudo dos serviços e técnicas de processamento da informação e seus sistemas de programação. Aceita-se o enfoque interdisciplinar com que tem sido tratada, dada sua relação com vários campos como a lógica, a lingüistica, a psicologia, a informática, a estatística, as operaçóes de pesquisa, as comunicaçôes, a biblioteconomia, a gestão e outros campos limitrofes. Complementando, concebe-se a CI como uma ciência social dotada de um domínio teórico-metodológico específico construído com a contribuição de outras disciplinas integrantes do mesmo 
núcleo como a arquivística, a biblioteconomia e a documentação e tangenciando as ciências sociais e humanas, como a história, a sociologia, a antropologia, a psicologia cognitiva e social e as ciências da educação. Seu campo de estudo abrange a gestão da informação, a produção, organização, representação e transferência da informaçáo e o comportamento informacional.

\section{Epistemologia e Ciência da Informaçáo}

Antes de estudar a Epistemologia da Ciência da Informação entende-se como necessária uma reflexão prévia sobre o que venha ser Epistemologia. Para tanto, buscouse fundamentação teórica na obra de "Introdução ao pensamento epistemológico", de Japiassu (1992) que pondera, de forma sucinta sobre as diversas concepçóes que o termo foi adquirindo na literatura filosófica.

Para o autor, "por epistemologia [...] podemos considerar o estudo metódico e reflexivo do saber, de sua organização, de sua formação, de seu desenvolvimento, de seu funcionamento e de seus produtos intelectuais" (Japiassu, 1992, p. 16). Em outras palavras, cabe à epistemologia refletir tanto sobre a teoria quanto a sobre a prática das ciências, desde seu início, estruturação, formação e progresso, contribuindo assim para consolidação do domínio científico.

O pensamento epistemológico busca aporte em suas quatro disciplinas. A primeira é a Filosofia das Ciências que tem a função de discutir "como a ciência é possível" ou "determinar valor e os limites do conhecimento para extrair sua natureza, mecanismo geral e seu alcance" (1992, p. 30). A História das ciências, por sua vez, é tida como essencial para a epistemologia, pois, ao mesmo tempo que discute a finalidade da ciência, analisa seu caminhar, destino e também sobre aquilo que a interessa, que a ocupa, em conformidade com que ela se propóe (1992, p. 33). A Psicologia das ciências, disciplina nova, é encarregada de responder a questão de "como crescem os conhecimentos" e foi influenciada por Piaget. A quarta disciplina seria a Sociologia do conhecimento, que se propóe a estudar a produçáo do conhecimento - aqui conhecimento considerado como construção social inserido em um contexto sóciocultural - tanto sob o ponto de vista lógico, quanto lingüístico, sociológico, ideológico, ou seja, em ótica interdisciplinar (1992, p. 39).

Observa-se que Japiassu desenvolve o tema enfatizando as abordagens não positivistas do pensamento epistemológico. Ou seja, para ele a epistemologia deve ser compreendida como teoria do conhecimento, conhecimento este tratado como processo náo mais como estado, como era tido pela corrente epistemológica do empirismo lógico. Por esta razão, o autor elege as correntes epistemológicas genética, de Piaget, histórica, de Bacherlard, racionalista-crítica, de Popper e arqueológica, de Foucault, como posiçóes filosóficas que se preocupam "com a história da ciência, com a história da inteligência, com a arqueologia das ciências e com as relaçôes da ciência com a sociedade.” (1992, p. 11)

O empirismo lógico ou neopositivismo sustenta a "instauração de critérios de sentido inspirada na própria prática das ciências”, partindo do propósito de delimitar de modo preciso o domínio das linguagens empíricas e descrever com o máximo de rigor possível o estatuto metodológico das ciências positivas, [...] reduzindo todo conteúdo do conhecimento a determinaçôes observáveis, de modo a [...] obter confirmação somente 
pela realidade" (1992, p. 87). Esta corrente apregoa que em qualquer hipótese deve haver sempre uma referência à experiência. Desse modo, a "linguagem metodológica torna-se [...] o instrumento fundamental da filosofia, sobretudo em sua forma válida, isto é, na forma de teoria da ciência” (1992, p. 88).

Divergindo do empirismo lógico ao enfocar o sujeito individual em uma perspectiva cognitivista, Piaget procura "fundar a construção de uma estrutura de conhecimento ou de ação em interação com as atividades do sujeito constituinte, a psicogênese culmina, de fato, em análises genéticas formalizadas e, por conseguinte permite a descoberta de um estatuto científico para as principais estruturas operatórias das ciências humanas" (1992, p. 45). Para ele, a epistemologia é "[...] uma espécie de anatomia comparada das estruturas mentais do sujeito cognoscente" (1992, p. 46). Isto é, diferentemente do empirismo lógico, Piaget defende a "elucidação da atividade científica a partir de uma psicologia da inteligência" e da construção do conhecimento (1992, p. 55).

Também em contraposição ao empirismo lógico, porém adotando uma postura mais voltada para aspectos históricos, Bachelard defende uma ciência cuja criação do conhecimento científico seja fundamentada na construção/produção/retificação, em detrimento da observação. Ou nas palavras do próprio Bachelard: "Só há ciência por uma escola permanente" (apud Japiassu, 1992, p. 70). Para tanto, se propôs a construir uma epistemologia visando à produção de conhecimentos principalmente sob seu aspecto histórico. Para ele, as ciências nascem e evoluem em circunstâncias históricas bem determinadas. Sendo assim, a epistemologia deverá interrogar-se sobre as relaçóes entre a ciência e sociedade, entre a ciência e as diversas instituiçóes ou entre as diversas ciências (1992, p. 66).

Apesar de influenciado pelo neopositivismo do Círculo de Viena, Popper pode ser considerado seu primeiro opositor, pois considera "as teorias científicas como livres criaçóes do nosso espírito, como resultado de uma tentativa feita para compreendermos intuitivamente as leis da natureza” (1992, p. 95). Ou seja, para ele náo é possível demonstrar as teorias via observação, mas somente testá-las com a finalidade de confirmá-las ou falsificá-las parcialmente. Popper utiliza a análise lógica para criticar o cientificismo metodológico, o objetivismo científico e a busca da verdade absoluta, considerando que a ciência pode fornecer apenas um conhecimento provisório. Em relação a esse aspecto, segue a mesma linha de pensamento de Bachelard, quando este afirma que o conhecimento deve ser constantemente retificado.

Compartilhando a visão histórica de Bacherlad, Foucault, no entanto, com sua arqueologia visa à descoberta dos fundamentos da ciência, ou seja, para ele o campo epistemológico onde da ciência se situa não trata da ciência em si, mas da base sobre a qual a ciência se constrói. Ou seja, propóe um estudo de uma "teoria do dispositivo que funda o sistema das ciências, seu campo epistemológico e sua história" (1992, p. 126).

A CI tem utilizado, desde sua origem, algumas dessas abordagens epistemológicas, "apresentando-se ora como ciência empírico-analítica, ora como meta-ciência, ainda que nos últimos anos tenha explorado, achamos que com maiores perspectivas, um pluralismo metodológico próprio das ciências sociais e de um campo interdisciplinar" (Gónzalez de Gómez, 2001, p. 13). 
Capurro (2003) compartilha da visão de Gónzalez de Gómez (2001), quando estabelece os três paradigmas da CI. O paradigma físico associado à área de Teoria Matemática da Informação de Shannon e Weaver, de 1972, cuja principal preocupação é a transmissão da informação, isto é, a informação é tratada apenas como sinais elétricos. Verifica-se que o paradigma físico é todo baseado na perspectiva epistemológica do Empirismo Lógico. Já o paradigma cognitivo, está relacionado com as interações entre a informação e o sujeito individual, ou seja, claramente se percebe a influência da Epistemologia Genética de Piaget e Epistemologia de Popper ${ }^{1}$. Por fim, o paradigma social que propóe a extensão dos estudos das interações entre a informação e o indivíduo para entre a informação e um contexto histórico e social. Aqui se observa a influência de Bachelard e Foucault.

Antes de Capurro, Saracevic (1996) em seu trabalho "Ciência da informação: origem e evolução" faz uma abordagem evolutiva da CI. Evidencia que com o passar do tempo, em função das mudanças de contexto histórico, os conceitos passavam a enfatizar as relaçóes entre a informação antes voltada para o processo, depois para o indivíduo, e por último para a sociedade.

Segundo Saracevic foi Borko, em 1968, o primeiro a conceituar CI e em 1970 Goffman estabeleceu outro conceito mais específico para o campo, conforme as citaçōes abaixo:

CI é a disciplina que investiga as propriedades e o comportamento da informaçáo, as forças que governam seu fluxo, e os meios de processá-la para otimizar sua acessibilidade e uso. A CI está ligada ao corpo de conhecimentos relativos à origem, coleta, organização, estocagem, recuperação, interpretação, transmissão, transformaçáo e uso de informação... Ela tem tanto um componente de ciência pura, através da pesquisa dos fundamentos, sem atentar para sua aplicação quanto um componente de ciência aplicada, ao desenvolver produtos e serviços. (Borko apud Saracevic, 1996, p. 45-46).

O objetivo da disciplina CI deve ser o de estabelecer um enfoque científico homogêneo para estudo dos vários fenômenos que cercam a noção de informaçáo, sejam eles encontrados nos processos biológicos, na existência humana ou nas máquinas... Conseqüentemente, o assunto deve estar ligado ao estabelecimento de um conjunto de princípios fundamentais que direcionam o comportamento em todo processo de comunicação e seus sistemas de informação associados... (A tarefa da CI) é o estudo das propriedades dos processos de comunicaçáo que devem ser traduzidos no desenho de um sistema de informação apropriado para uma dada situaçáo física. (Goffman apud Saracevic, 1996, p. 46).

1 "De certa forma, a própria passagem das abordagens físicas para as cognitivistas sinaliza uma reação inicial que se manifesta com a criação de um "objeto mental". A informação-coisa é agora vista como uma imagem mental. Na literatura de campo, surgem inúmeras referências a Popper, com seu terceiro mundo de objetos inteligíveis (formulaçóes lingüísticas compartilháveis, teorias, modelos e postulados de conhecimento sobre o mundo [...]" (Campos; Venâncio, 2007, p. 110) 
Tomando a pesquisa de Saracevic como base, considera-se que, as discussōes da década de 60 em torno da CI foram representadas pelos conceitos expostos acima. Ao analisá-los, percebe-se que em ambos a preocupação central é a organização da informação voltada basicamente para sua recuperação. Isto é, a ênfase é dada para o processo. Assim como no paradigma físico de Capurro, aqui se verifica novamente a influência epistemológica do Empirismo Lógico.

$\mathrm{Na}$ primeira fase histórica da CI, a figura do usuário de informação, bem como a assimilação da informação por ele náo é considerada como parte fundamental do processo. O sujeito começa a ser visto com mais importância, a partir da década de 70, com Kochen, em 1974, Belkin e Robertson (1976) e Becker (1976). Este período é marcado pela inserção dos estudos de ciências cognitivas na CI principalmente no que se refere aos processos mentais de assimilação, interpretação e uso da informação pelo indivíduo, conforme os conceitos abaixo:

Podemos conceitualizar o sistema de conhecimento, no qual se inscreve a recuperação de informação, como composto por três partes; (a) as pessoas em seu papel de processadores de informaçóes; (b) os documentos em seu papel de suportes de informações; (c) os tópicos como representaçóes. Estamos interessados no ciclo de vida de cada um destes três objetos e na dinâmica deinteração entre eles. Portanto, devemos considerar a variável comum aos três tempos. (Kochen apud Saracevic, 1996, p. 47).

Belkin e Robertson (1976) dizem que "o propósito da CI é facilitar a comunicação de informaçôes entre seres humanos”; Becker (1976) definiu a CI como o estudo do modo pelo qual as pessoas "criam, usam e comunicam informaçôes". (Saracevic, 1996, p. 47). Mais uma vez, observa-se que a epistemologia da CI acompanha a tendência das discussóes epistemológicas sobre a ciência, pois o pensamento desta época, também conhecida como paradigma cognitivo por Capurro, fundamenta-se nos projetos de Piaget e Popper.

Ainda de acordo com Saracevic, a partir da década de 80, devido ao relacionamento mais estreito da CI com a área de Administraçáo, bem como, o desenvolvimento da tecnologia da informaçáo, o eixo da CI passou a ser o contexto social da informação, ou seja, o uso da informação para a criação de conhecimento tanto individual como coletivo. A prática profissional da CI figura como a preocupação principal nesta fase. Em 1990, o próprio Saracevic elabora um novo conceito de CI como

[...] um campo dedicado às questóes científicas e à prática profissional voltada para os problemas da efetiva comunicação do conhecimento e de seus registros entre os seres humanos, no contexto social, institucional ou individual do uso e das necessidades de informaçáo. No tratamento destas questôes são consideradas de particular interesse as vantagens das modernas tecnologias informacionais. (Saracevic, 1996, p. 47). 
Capurro e Saracevic a CI partindo da perspectiva de paradigmas, de acordo com $\mathrm{Kuhn}^{2}$, segundo a qual a CI teria surgido com um paradigma físico, questionado por um enfoque cognitivo. Este, por sua vez, substituído por um paradigma pragmático e social (Capurro, 2003). A crítica de Wersig (apud Campos e Venâncio, 2007) de acordo com uma perspectiva realista, à visão paradigmática reside no fato de que poderia haver a promoção de uma competição entre eles, tratando-se de uma abordagem que não está direcionada a questôes específicas e suas resoluçôes, interferindo no exercício transdisciplinar, em detrimento do enfoque multidiscilpinar, que a área deveria colocar em prática. Segundo Campos e Venâncio (2007, p. 109), a CI deve ser evidenciada em seu "processo não-linear de fundação e reconfiguração".

Em função deste desenvolvimento não-linear da CI, Wersig (1993) propóe que ela seja vista náo como uma ciência tradicional que tem um único objeto de estudo, mas sim como uma "nova ciência" ou uma ciência pós-moderna que pode ter múltipos objetos, conceitos, inter-conceitos e métodos. O autor parte da crítica à necessidade de estabelecer um estudo baseado em paradigmas na CI nos moldes das ciências tradicionais, como tentativa de atestar sua cientificidade. Para sustentar tal proposta, Wersig se fundamenta principalmente nas teorias de Feyerabend, Habermas e Luhmann.

Visto que na pós-modernidade a informação e o conhecimento são considerados como recursos essenciais para do desenvolvimento econômico e social, a CI figura ao mesmo tempo como fruto e como promessa de soluçóes para dos problemas decorrentes dessa tendência. Pode-se inferir que a CI nasceu com e para a pós-modernidade reparar as conseqüências provocadas pela modernidade, como por exemplo, a explosão da informação ${ }^{3}$. Porém, a CI ainda mantém características das disciplinas científicas da modernidade.

Para Araújo (2003) a CI "surge em um momento em que já se observavam as críticas e o início da crise que se abate sobre o modelo moderno da cientificidade". Entretanto, verifica que esta ciência, na tentativa de consolidação como domínio do saber, se constrói tanto nos moldes da ciência moderna como na ciência pós-moderna (2003, p. 26). A incorporação da teoria matemática da informação, de Shannon e Weaver, as leis de Zipf, de Bradford, a Bibliotemetria, a Infometria, a Cientometria, exemplificam elementos teóricos que compóe a CI provenientes da ciência moderna.

Seguindo esta linha, Le Coadic se posiciona em prol de uma definição epistemológica da CI nos moldes da ciência moderna, apesar de compartir com a idéia de uma mudança nas condiçôes do saber, decorrente do ingresso das sociedades na chamada era pósindustrial e das culturas na chamada era pós-moderna. Para tanto, ele argumenta que a "CI identificou e delimitou se objeto de estudo e problemas fundamentais de pesquisa: estudo das propriedades gerais (natureza, gênese e efeitos), dos processos e sistemas de construção, comunicação e uso da informação" (2003, p. 55). Ou seja, segundo o autor a CI conta com conceitos, métodos e leis científicos e técnicos considerados unívocos e que tendem à objetividade.

\footnotetext{
2 Segundo Kuhn, o paradigma indica "toda constelação de crença, valores, técnicas partilhadas pelos membros de uma comunidade determinada” (Kuhn apud Campos e Venâncio, 2007, p. 108).

3 “[...] crescimento exponencial na produção de conhecimento/informação e o avanço desmesurado das possibilidades tecnológicas para seu registro, circulação e divulgação.” (Cardoso, 1996, p. 73).
} 
Por outro lado, retomando o pensamento de Wersig, a CI possui outras características que permitem sua classificação como uma ciência pós-moderna. Assim como a pós-modernidade, a CI é marcada por uma falta de unidade teórica em muitos aspectos. A diversidade, a pluralidade e o indeterminismo, isto é, a incerteza acerca da suas origens, sobre seu objeto de estudo - a informação - e mesmo sobre seu conceito, estão significativamente presentes no âmbito desta ciência. Este fato não poder ser atribuído somente aos poucos e recentes esforços de estudar mais a teoria da área, ou ao fato da CI ser uma nova ciência, mas também pela sua complexidade.

Além da complexidade, outra característica que reforçaria a tese de que a CI seja pós-moderna é a sua natureza interdisciplinar (Araújo, 2003, p. 26). A CI busca nas outras áreas do saber, não somente apropriação de conceitos, métodos, teorias e analogias, mas a contribuiçáo de novos conhecimentos em numa relação de troca, reciprocidade e aproveitamento mútuos.

As características epistemológicas da CI podem ser levantadas por meio da análise da literatura, sobretudo a periódica, que por sua vez é considerada mais importante na área. Sendo assim, julgou-se necessário verificar como se configura epistemologicamente esta ciência via análise de citaçóes, e conseqüentemente de influências teóricas, dos artigos científicos da área que versam sobre o tema Epistemologia da CI.

\section{Produção Científica na Literatura Periódica Brasileira em CI}

Os periódicos científicos são por excelência os meios mais eficazes de comunicação científica, desde o século XVII. De acordo com Meadows (1999, p. 7), o motivo principal pelo qual surgiram os periódicos encontra-se na necessidade de comunicação, do debate coletivo de forma eficiente procurando a partir disto a realização de novos descobrimentos. Desde então, o crescimento da produção periódica acompanhou a expansão da ciência e da comunidade científica, e também passou a ser fundamental para atualização deste público.

Diante disto, os periódicos representam grande parte da consolidação do conhecimento desenvolvido por uma ciência. Portanto, ao estudar a consolidaçáo de qualquer ciência como domínio do conhecimento não se pode desconsiderar a relevante contribuição registrada nos periódicos científicos. De acordo com Tenopir e King (2001, p. 23),

a informação contida nos periódicos se presta a muitas finalidades (pesquisa, ensino, serviços de alerta, leitura básica, etc.) para os cientistas, tanto no contexto universitário quanto no não universitário [...] eles relatam que os artigos são de grande importância para seu trabalho, mais do que qualquer recurso informacional.

Sendo assim, considera-se que o estudo diacrônico da produção em revistas científicas oferece perspectivas para compreender a história da construção intelectual de áreas do conhecimento específicas, possibilitando a reflexão sobre tendências da literatura científica e influências teóricas. (Bufrem, 2006, p. 194) 
Os primeiros periódicos científicos brasileiros da área de CI surgiram somente na década de 1970. "Em 1972, foram criados a Ciência da Informação, sob a responsabilidade do IBICT, e a Revista da Escola de Biblioteconomia da UFMG, que teve seu título alterado em 1996 para Perspectivas em Ciência da Informação, editada pela Escola de Ciência da Informação da UFMG" (Andrade e Oliveira, 2005, p. 52) ${ }^{4}$. No ano seguinte, foi criada a Revista Brasileira de Biblioteconomia e Documentaçáo, pela Federação Brasileira de Associações de Bibliotecários (FEBAB). Somente em 1989, o Mestrado de Biblioteconomia da PUC-Campinas passou a editar a próxima revista da área: a Transinformação. Em 1991, o Mestrado em Biblioteconomia da Universidade Federal da Paraíba criou o título Informação \& Sociedade: Estudos e, no final desta década, passa a ser publicada via Internet pelo Instituto de Adaptação e Inserção na Sociedade da Informação (IASI) a revista Datagramazero. Depois, outras publicaçôes essencialmente eletrônicas surgiram: a Encontros Bibli: revista de Biblioteconomia e Ciência da Informação, do Mestrado em Ciência da Informação da Universidade Federal de Santa Catarina, em 2002; a Revista Biblos, do Departamento de Biblioteconomia e História, da Fundação Universidade do Rio Grande; e recentemente a Revista Digital de Biblioteconomia e Ciência da Informação, do Sistema de Bibliotecas da UNICAMP (Bufrem, 2006, p. 200).

A produção de revistas científicas no Brasil, especialmente em áreas as quais a consolidação científica ainda se encontra em construção como a CI, refletem as dificuldades devido a problemas de estabilidade política e financeira enfrentas pelo país. Além disso,

[...] a Ciência da Informaçáo conta com uma infra-estrutura, ainda incipiente, de ensino e pesquisa, uma vez que seu apoio institucional está em fase de implantaçáo. Para o desenvolvimento das atividades científicas, torna-se necessária uma infraestrutura mínima composta por elementos básicos, a saber: instituiçóes de ensino e pesquisa fortes, bem como apoio às atividades de pesquisa, recursos humanos qualificados e canais de comunicação e intercâmbio científico (Andrade e Oliveira, 2005, p. 46).

\section{Metodologia e Resultados}

O corpus da pesquisa é constituído por todos os artigos de periódicos registrados na base BRAPCI. Esta base de dados é o produto de informação do projeto de pesquisa "Opções metodológicas em pesquisa: a contribuição da área da informação para a produção de saberes no ensino superior", cujo objetivo é subsidiar estudos e propostas na área de Ciência da Informação, fundamenta-se em atividades planejadas

${ }^{4}$ Enquanto no Brasil a CI dava seus primeiros passos, no mundo ela já havia evoluído, já tinha mudado seu eixo do processo de organização e recuperação da informação para, além o processo, a assimilação da informação pelo usuário. Diante disto, adota-se aqui a hipótese de que nos anos 1970 a "CI brasileira" ainda estava preocupada somente com o processo. 
institucionalmente. Com esse propósito, foram identificados os títulos de periódicos da área de CI e indexados seus artigos, constituindo-se a base de dados referenciais.

Uma análise preliminar da BRAPCI permitiu a identificaçáo e recorte de 95 artigos que versam sobre questóes epistemológicas relativas ao campo da CI no Brasil, no período de 1972 a 2008. Os descritores de busca utilizados na recuperação dos artigos na BRAPCI foram: epistemologia; teoria do conhecimento; teoria da ciência; teoria da CI; história da ciência; ciência da ciência; filosofia da ciência, gnosiologia e epistemológico(a).

Com base no recorte de artigos procedeu-se uma análise de citação com o objetivo de levantar os autores nacionais mais citados pelos dez pesquisadores mais produtivos da área no Brasil e suas principais influências teóricas internacionais.

Dessa forma, foi possível descobrir os autores basilares na área epistemológica da CI no Brasil e os teóricos da área de epistemologia mais citados por estes autores.

\section{Análise e Discussão dos Resultados}

Os resultados da análise de citaçóes apresentados no gráfico 1 apontam Maria Nélida González de Gómez (com 27 citaçôes) como principal autora de Epistemologia da CI no Brasil, destacando-se entre seus títulos "A informação como instância de integração de conhecimentos, meios e linguagens: questóes epistemológicas, conseqüências políticas", "Da organização do conhecimento às políticas de informaçâo", "Metodologia de pesquisa no campo da Ciência da Informação", "O contrato social da pesquisa: em busca de uma nova equação entre a autonomia epistêmica e autonomia política", de 2006; " $A$ vinculação dos conhecimentos: entre a razão mediada e a razão leve", de 2005; "Novas fronteiras tecnológicas das açôes de informação: questôes e abordagens", de 2004; "As relaçóes entre ciência, Estado e sociedade: um dominio de visibilidade para as questóes da informação", de 2003; "Dos estudos sociais da informação aos estudos do social desde o ponto de vista da informação", 2002; "O caráter seletivo das açóes de informação", "Metodologia da pesquisa no campo da Ciência da Informação", de 2000; "Da organização do conhecimento às políticas de informação", de 1996; "A informação: dos estoques às redes", de 1995; "Da representaçâo do conhecimento ao conhecimento da representaçâo", de 1993; "O objeto de estudo da Ciência da Informação: paradoxos e desafios", de 1990; "O papel do conhecimento e da informação nas formaçôes políticas ocidentais", de 1987; "A configuração temática de ciência da informação no currículo dos cursos do IBICT: estudo do caso", de 1982.

Com vinte citações, aparece Boaventura Santos com os títulos: "Introduçâo à uma ciência pós-moderna", "Um discurso sobre as ciências" e "A crítica da razão indolente: contra o desperdicio da experiência”. Em seguida, com 19 citações aparecem Emília Currás e Antonio García Gutiérrez. Entre nove e sete citaçóes verificam-se os nomes de Solange Mostafa, Rosaly Favero Krzyzanowski, Aldo Barreto, M. C. Cavalcanti, Maria Lopez Ginez de Lara e Lena Vânia Pinheiro. 
Fig. 1 - Autores mais representativos da produção sobre questões epistemológicas na literatura periódica da área de CI

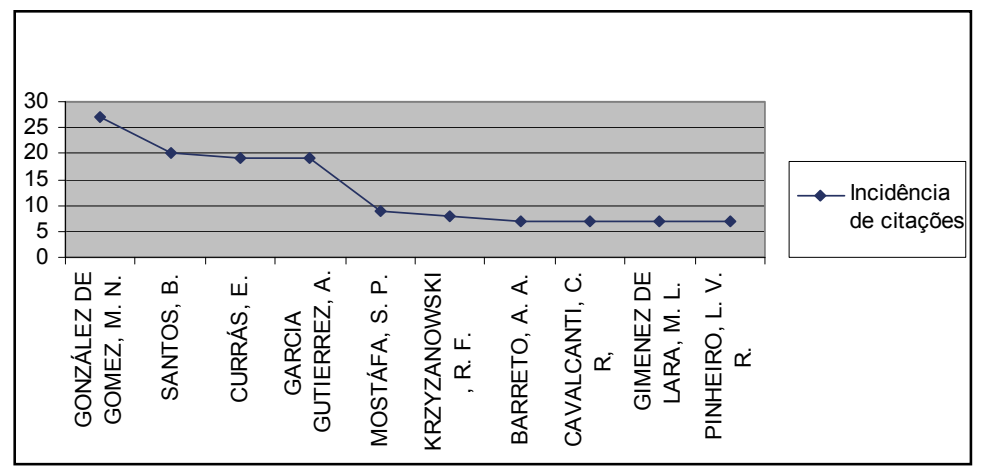

Em relação ao gráfico 2, verifica-se ainda a incidência de autores oriundos de basicamente três áreas do conhecimento. Da CI: Capurro, Wersig, Saracevic, Shera, Mikhailov, Brookes, Belkin, Buckland e Shannon. Da filosofia da ciência: Morin, Latour, Kuhn, Focault, Japiassu, Frohmann, Lakatos, Popper, Bachelard, Prigogine, Feyerabend, Moles e Habermas. E por fim, da sociologia, Castells.

Fig. 2 - Teóricos da área de epistemologia mais citados pelos dez autores mais representativos da produção sobre questôes epistemológicas na literatura periódica da área de CI

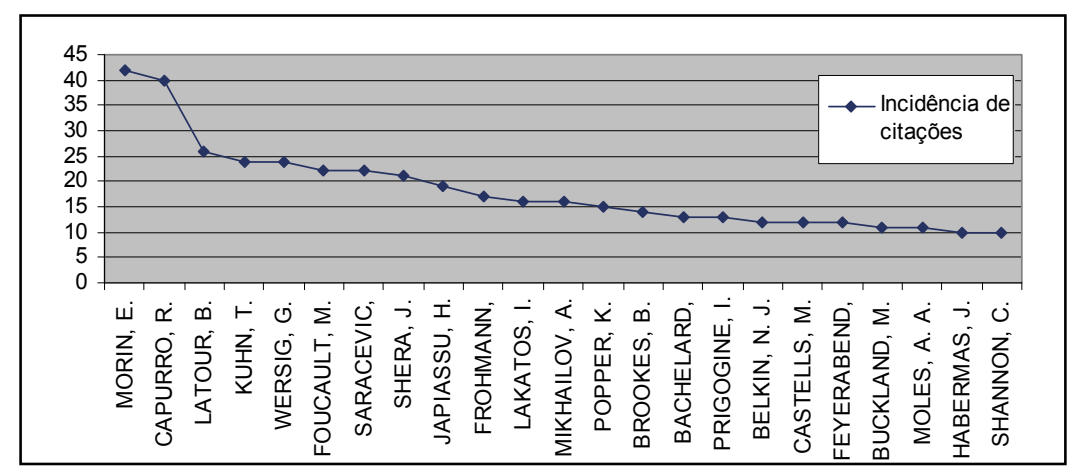

Destaca-se Morin como o mais citado dos autores "fundantes" (42 registros), de modo especial por seus estudos sobre a complexidade, característica determinante da crise de modernidade, principalmente no âmbito científico. Para Morin, a complexidade surge como dificuldade, como incerteza e não como clareza e como resposta, problematizando sobre a possibilidade de responder ao desafio da incerteza e da dificuldade. $\mathrm{O}$ autor tem expressiva presença na literatura sobre a transdisciplinaridade, considerada como alternativa para o desenvolvimento da ciência, em detrimento de uma visão essencialmente positivista e suas obras representativas nesse corpus foram: "Introdução 
ao pensamento complexo" (1990); "O paradigma perdido: a natureza humana" (1991); "As grandes questôes do nosso tempo" (1994); "O problema epistemológico da complexidade" (1996); "O método 3: o conhecimento do conhecimento" (1999); "Por uma reforma do pensamento" (1999); "A inteligência da complexidade" (2000); "A cabeça bem feita: repensar a reforma, reformar o pensamento" (2002); "A ciência com consciência" (2002) e "O método 1: a natureza da natureza" (2002).

Distinguido com quarenta citaçóes, Capurro enfoca o tema Epistemologia da Ciência da Informação, adotando uma visão paradigmática, fundamentada em Kuhn e sustentando sua teoria sobre o desenvolvimento da CI em três paradigmas: físico, cognitivo e social, de modo a compor teoricamente o que passou a ser conhecido como o Trilema de Capurro. Destacam-se seus títulos "Epistemologia e Ciência da Informação" (2003), "Angeletics: a message theory" (2003), "Foundations of information science: review and perspectives" (2003); "Heidegger y la experiencia del lenguaje" (1982), "Hermeneutics and the phenomenon of information" (2000), "What is Information Science for? A Philosofical Reflection" (1992), "Is a unified theory of information feasible? A trialogue" (2004) e "The concept of information" (2006).

Representados numa segunda faixa, entre 24 e 19 citaçóes, aparecem Latour, com seu título "Ciência em ação" (2000); Kuhn e sua obra principal "As estruturas das revoluçôes cientificas"; Wersig, com o polêmico artigo "Information science: the study of postmodern knowledge usage"; Foucault, com principalmente "A arqueologia do saber"; Saracevic, com "Ciência da Informação: origem, evolução e relaçóes", de 1996; Shera, com o artigo de 1976, "Toward a theory of librarianship and information science" $\mathrm{e}$ Japiassu, com destaque para as obras "Introdução ao pensamento epistemológico" (1970) e "Interdisciplinaridade e patologia do saber" (1986).

Situados em uma terceira faixa (entre 17 e 10 citaçóes) aparecem Frohmann, Imre Lakatos, Mikhailov, Popper, Brookes, Bachelard, Prigogine, Belkin, Castells, Feyerabend, Buckland, Moles, Habermas e Shannon, representando posiçóes diversas, embora em certos casos relacionadas. É o caso de Lakatos, que valorizou o pensamento popperiano como o desenvolvimento filosófico mais importante do século XX, sem deixar de considerar as críticas que recebeu de Kuhn e Feyerabend.

A atribuiçấo dada a CI como uma ciência marcada pela complexidade, pela interdisciplinaridade e mesmo a transdisciplinaridade é sustentada pela significativa incidência de autores como Morin, Japiassu, Saracevic, Krzyzanowski e Pinheiro.

Nos dois gráficos verifica-se a forte presença de autores que abordam a temática da pós-modernidade e defendem a CI como uma ciência pós-moderna. Dentre estes, se destacam Boaventura Santos e Wersig. O aparecimento de autores como Foucault, Prigogine, Feyerabend e Castells reforça esta tendência.

No entanto, vale ressaltar que esta concepção não é unânime na área, pois ainda há influência dos autores que estudam a CI nos moldes da ciência moderna como Buckland, Shannon e Mikhailov principalmente. A freqüência de autores cujos estudos descartam a idéia de pós-modernidade como Latour e Habermas sugere a presença de uma crítica à concepção pós-moderna da CI. Neste sentido, em contraposição ao pensamento pós-moderno também se observa ainda a influência significativa da visão paradigmática, representada principalmente por Capurro, Saracevic e Kuhn.

Há que se considerar as concepçôes de autores como González de Gómez, Currás, García Gutierrez, Mostafa, Krzyzanowski, Barreto, Frohmann, Shera, Latour, Habermas, 
Bachelard, Castells e Moles como decorrentes de posiçóes que privilegiam os aspectos social, histórico e político da CI. Por sua vez, Belkin, Popper, Lakatos, Brookes, Cavalcanti e Gimenez de Lara privilegiam os aspectos cognitivo e lingüístico.

\section{Consideraçóes Finais}

A análise de citaçôes da literatura periódica representa uma complexa rede de relaçóes temáticas presente nas reflexóes sobre aspectos epistemológicos relacionados à CI, já antes relevada mediante o estudo teórico. Por meio do estudo empírico foi possível estabelecer uma configuração representativa do estado das questôes epistemológicas no âmbito da CI. As principais características levantadas foram diversidade de linhas de pensamento, o predomínio de abordagens de cunho social em detrimento de abordagens exatas e cognitivas e a ênfase dada a temas como complexidade, inter e transdicisplinaridade, pós-modernidade e paradigmas.

A diversidade de linhas de pensamento adotadas pelos autores levantados demonstra intenso pluralismo presente no campo teórico da CI. No entanto, observa-se o predomínio de abordagens de cunho social, histórico e político, que tratam a CI como uma ciência social, principalmente no gráfico 1, representadas pelos autores González Gomez, Currás, García Gutierrez, Mostafa, Krzyzanowski e Barreto, e no gráfico 2, por Frohmann, Shera, Latour, Habermas, Bachelard, Castells e Moles. Também se destaca a influencia significativa dos teóricos considerados pós-modernos, como Boaventura Santos, Wersig, Foucault, Prigogine, Feyerabend e Castells. O aparecimento de autores que ressaltam temas como a complexidade, a inter e transdisciplinaridade da CI, como Morin, Japiassu, Saracevic, Krzyzanowski e Pinheiro reforçam a preponderância do pensamento pós-moderno. Este, não somente leva em consideração essas temáticas, mas defende que a complexidade, a inter e transdisciplinaridade são algumas das principais características do movimento.

Porém, a incidência de autores, mesmo que pouco expressiva, como Habermas e Latour mostra que a área não se encontra imune às críticas ao movimento pósmoderno, além, da presença de Buckland, Shannon e Mikhailov, que por sua vez, tratam a CI como ciência exata e Belkin, Popper, Lakatos, Brookes, Cavalcanti e Lara que, privilegiando o aspecto cognitivo e lingüístico, permitem que se reflita sobre a CI como uma ciência humana. E ainda, há considerável parcela de trabalhos que têm uma visão paradigmática da CI, como os de Capurro, Saracevic e Kuhn.

Além da diversidade de pensamento, outro ponto a ser notado é a presença, ainda que com diferentes intensidades, das abordagens social, cognitiva e exata, sugerindo a insustentável posição de uma visão essencialmente paradigmática. Em outras palavras, retoma-se o pensamento de Wersig (1993) contra a concorrência entre as três abordagens.

Também vale ressaltar que o debate epistemológico nacional da CI acompanhou as tendências de debate do campo epistemológico. A influência de autores provenientes dos campos filosóficos e sociológicos, detectada pela incidência de citaçóes, confirma este fato. Pode-se perceber ainda a marcante influência de autores estrangeiros de todos os campos, sendo Hilton Japiassu o único teórico brasileiro que aparece no gráfico 2 . 
Apesar de acompanhar os debates epistemológicos, a presença de somente 95 artigos em um universo de quase 5.000 mostra que os estudos nesta área ainda podem ser considerados incipientes, em decorrência da intensa flutuação e multiplicidade de pensamento indicativa de uma ciência cujas questôes mais prementes apresentam-se como estágio preliminar de discussóes epistemológicas mais intensas no contexto da CI no Brasil.

\section{Referências bibliográficas}

Andrade, M. E. A.; Oliveira, M. (2005). A ciência da informação no Brasil. In: OLIVEIRA, M. Ciência da informação e Biblioteconomia: novos conteúdos e espaços de atuação. Belo Horizonte: UFMG. p. 45-56.

Araújo, C. A. A. (2003). A ciência da informação como ciência social. Perspectivas em Ciência da Informação, 32 (3), 21-27.

Bufrem, L. S. (2006). Revistas científicas: saberes no campo da ciência da informaçâo. Journal of the American Society for Information Science, 45, 12-19.

Campos, L. F. B.; Venâncio, L. S. (2007). Perspectivas em (in)formação: tendências e tensões entre abordagens físicas, cognitivistas e emergentes. Transinformação, 19, 107-118.

Capurro, R. (2003). Epistemologia e Ciência da informação. In: ENCONTRO NACIONAL DE PESQUISA EM CIÊNCIA DA INFORMAÇĀO, 5., Belo Horizonte, 2003. Anais... Belo Horizonte: Escola de Ciência da Informação da UFMG.

Cardoso, A. M. P. (1996). Pós-modernismo e informação: conceitos complementares? Perspectivas em Ciência da Informação, 1 (1), 63-79.

Castro, C. A. (2006, jan./abr.). O periódico no campo da biblioteconomia no Brasil: possibilidades para um fazer historiográfico. Transinformação, Campinas, 18 (1), p. 9-15.

González de Gómez, M. N. (2001). Para uma reflexão epistemológica acerca da Ciência da Informação. Perspectivas em Ciência da Informação, 6 (1), 5-18.

Japiassu, H. (1992). Introdução ao pensamento epistemológico. 7. ed. Rio de Janeiro: F. Alves.

Le Coadic, Y. F. (2003). A Ciência da Informação. 2. ed. Brasília: Briquet de Lemos/Livros.

Meadows, A. J. (1999). A comunicação científica. Brasília, DF: Briquet de Lemos.

Saracevic, T. (1996). Ciência da informação: origem, evolução e relaçôes. Perspectivas em Ciência da Informaçâo, 1, 41-62, jan./jun.

Tenopir, C. K., D. W. (2001). A importância dos periódicos para o trabalho científico. Revista de Biblioteconomia de Brasilia, 25 (1), 15-26, jan./jun.

Wersig, G. (1993). Information science: the study of postmodern knowledge usage. Information Processing \& Management, 29, 2. 